\title{
A standardized method to purify cardiomyocytes from individual mouse hearts of any age
}

\begin{abstract}
Amy M Nicks ${ }^{1,2}$, Sara R Holman ${ }^{1}$, Andrea Y Chan ${ }^{1}$, Michael Tsang ${ }^{1}$, Paul E Young ${ }^{1,2}$, David T Humphreys ${ }^{1,2}$, Nawazish Naqvi ${ }^{3}$, Ahsan Husain ${ }^{3}$, Ming Lij ${ }^{1,4}$, Nicola J Smith ${ }^{1,2}$, Siiri E lismaa ${ }^{1,2}$ \& Robert M Graham ${ }^{1,2}$
\end{abstract}

${ }^{1}$ Division of Molecular Cardiology and Biophysics, Victor Chang Cardiac Research Institute, Sydney, NSW 2010 \& ${ }^{2}$ St Vincent's Clinical School, University of New South Wales, Sydney, NSW 2052, Australia; ${ }^{3}$ Department of Medicine (Cardiology), Emory University School of Medicine, Atlanta, GA, USA; ${ }^{4}$ Cardiac Regeneration Research Institute, Wenzhou Medical University, Wenzhou, 325035, China

*Corresponding author:

Robert M Graham, or Siiri E lismaa, Division of Molecular Cardiology and Biophysics, Victor Chang Cardiac Research Institute, 405 Liverpool Street, Darlinghurst, NSW 2010, Sydney, Australia, Tel: +61 (0)2 9295 8677, E-mail: b.graham@victorchang.edu.au or s.iismaa@victorchang.edu.au 


\section{Abstract}

Rationale: Primary cardiomyocytes are invaluable for understanding postnatal heart development and elucidating disease mechanisms in genetic and pharmacological models, however, a method to obtain freshly purified cardiomyocytes at any postnatal age, without using different age-dependent isolation procedures and cell culture, is lacking.

Objective: To develop a standardized method that allows rapid isolation and purification of cardiomyocytes in high yield and viability from individual neonatal, infant, and adult mice.

Methods and Results: Hearts of C57BL/6J mice were cannulated using a novel in situ aortic cannulation procedure optimized to allow cannulation of even the very small vessel of neonates (postnatal day 0-2, P0-2). Hearts were then subjected to Langendorff retrograde perfusion and enzymatic digestion. Cardiomyocytes were isolated after subsequent tissue disaggregation and filtration, in high yield (1.56$2.2 \times 10^{6}$ cardiomyocytes/heart) and viability ( 70-100\%). The larger size of infant (P10 and P13) and adult (P70), but not neonatal, cardiomyocytes relative to non-myocytes, allowed enrichment by differential centrifugation. Cardiomyocytes from all ages were further purified by immunomagnetic bead-based depletion of non-myocytes. Together, these procedures resulted in the isolation of highly purified cardiomyocytes ( 94\%) within 1 hour, enabling experiments using individual replicates. For example, RNAsequencing of cardiomyocytes purified from one P2 male and female heart per litter ( $n=4$ litters) showed distinct clustering by litters and sex differences for nine differentially expressed genes (FDR<0.005). In situ fixation via coronary perfusion, performed immediately after tissue digestion, preserved the cytoarchitecture of isolated cardiomyocytes (yielding $~ 94 \%$ rod-shaped cardiomyocytes at all ages), allowing capture of spindle-shaped neonatal cells undergoing mitosis, as well as enabling accurate quantitation of cardiomyocyte area and nucleation state.

Conclusion: The procedures developed here provide a universal protocol for the rapid isolation and purification of high-quality cardiomyocytes from hearts of any postnatal age, even those of neonates, thereby enabling direct comparisons between individual hearts. 


\section{Introduction}

In mammals, postnatal heart development is characterized by a remarkable increase in mass that is required for normal cardiovascular responses in the adult animal. Cardiac growth is influenced by a variety of factors, including nutrition, hypoxia, prematurity, endocrine stress, and congenital and acquired heart diseases $^{1-3}$. The molecular events involved in cardiomyocyte maturation and the early origins of cardiovascular disease are not well understood.

Investigation of cardiomyocyte ontogeny and disease-related alterations therein, is best achieved if the same method can be used to rapidly isolate and then purify cardiomyocytes in high yield and viability from animals of any developmental age. Methods used to generate isolated neonatal or adult rodent cardiomyocytes from the cardiac milieu are not trivial and have been continually modified and improved since the 1960 ' $\mathrm{s}^{4,5}$. Langendorff retrograde perfusion is the gold standard for isolating high quality adult cardiomyocytes $^{6}$, but has also been applied to isolating cardiomyocytes from 21 day-old mouse hearts ${ }^{7}$. To generate isolated neonatal cardiomyocytes, more rudimentary "batch chopping" procedures are used that involve crude mincing of hearts followed by sequential enzymatic digestion steps or an overnight digestion ${ }^{6,8}$. This protocol generally requires pooling of 5-15 PO-P3 hearts for a single replicate $\mathrm{e}^{6,8}$, thereby precluding evaluation of individual hearts from wild-type or genetically-modified mouse models, mice after surgical or pharmacological treatments, or mice of different sexes. To date, there is no universal method that can be used to isolate and purify cardiomyocytes from neonatal as well as adult hearts.

Langendorff perfusion and tissue disaggregation of adult hearts yields cardiac cell populations that include, for example, endothelial cells and fibroblasts. Cardiomyocytes are generally enriched by differential centrifugation ${ }^{9}$ or settling with gravity ${ }^{10}$ to remove a proportion of non-myocytes and may be further purified by cell culture $\left(<24 \mathrm{hr}\right.$ or up to $72 \mathrm{hr}$ ) or Percoll gradients ${ }^{6,9,10}$. Neonatal murine cardiomyocytes are generally purified, without enrichment, by differential cell culture, whereby cardiac cells are pre-plated onto an uncoated culture dish for several hours to allow non-myocytes to attach. Cardiomyocytes in the supernatant are then transferred to a collagen-coated culture dish for 12 hours to 3 days $^{8,11}$. Given the time-consuming incubations and nature of cell culture purification, they lead to morphological and functional changes as cells adapt to cell culture conditions, such as altered molecular composition (RNA, protein, metabolites), abnormal cytoarchitecture, cardiomyocyte dedifferentiation and cell death over time $e^{6,8}$. This is particularly problematic when these purified cardiomyocyte fractions are used for molecular, cellular, and functional studies. 
bioRxiv preprint doi: https://doi.org/10.1101/2021.09.30.462562; this version posted September 30, 2021. The copyright holder for this preprint (which was not certified by peer review) is the author/funder, who has granted bioRxiv a license to display the preprint in perpetuity. It is made available under aCC-BY-NC-ND 4.0 International license.

Here, we developed a standardized procedure using Langendorff perfusion and immunomagnetic cell separation to rapidly isolate and purify cardiomyocytes in high yield and purity to allow molecular studies from individual neonatal, infant, and adult murine hearts. A further advance was the application of in situ fixation to preserve cardiomyocyte cytoarchitecture that closely emulates the in vivo environment and, consistent with their contractile and replicative competence, enabled capture of isolated spindle-shaped neonatal cells undergoing mitosis. 


\section{Methods}

An expanded description of the procedure and a complete material list is available in the Online Data Supplement.

\section{Animals}

C57BL/6J mice were used at various ages, including neonates (postnatal day 0-2, P0-2), infants (P10 and P13) and P70 adults (9-11-week-old). Animals were housed in individually ventilated cages, given food and water ad libitum, and exposed to a 12-hr light-dark cycle. All studies were approved by the Garvan Institute /St Vincent's Hospital Animal Ethics Committee and performed in accordance with The Australian Code of Practice for the Care and Use of Animals for Scientific Purposes (2004).

\section{In situ aortic cannulation}

Animals were sacrificed by decapitation (SP10) or cervical dislocation (>P10) 20-30 min after an intraperitoneal injection of heparin (10, 20 and $100 \mathrm{IU}$ for neonate, infant, and adult mice, respectively). After sterilizing the chest with $70 \%$ ethanol, the thoracic cavity was then opened. Surgical instruments used for dissection and cannulation are shown in Figure $1 \mathrm{~A}$ and detailed in Online Table I. Tissues surrounding the heart, including lungs and esophagus, were removed (Figure 2); the thymus, heart and aorta were kept intact and separated from surrounding connective tissue by dissection. Under a dissecting microscope, the aorta was mobilized from the underlying spinal column, then transected at the level of the diaphragm and drawn onto a cannula (attached to a $10 \mathrm{~mL}$ syringe primed with perfusion buffer) until the tip was just above the aortic valve (Figure 2). The aorta was secured onto the cannula with 6-0 silk using a double knot, and the thymus removed prior to mounting the heart onto the Langendorff apparatus for perfusion (see Figure 1 and 2, Table 1 and Online Data Supplement). Note: using separate Langendorff rigs, one person can sequentially cannulate, mount and perfuse two hearts, enabling the purification of cardiomyocytes from an entire litter of 6-8 mice in a single day.

\section{Langendorff perfusion, cardiomyocyte isolation and enrichment}

Langendorff perfusion parameters were optimized for efficient digestion of neonatal and infant hearts (Table 1). Isolated cardiomyocyte preparations were generated as detailed in the Online Data Supplement. Differential centrifugation was used to enrich for infant and adult cardiomyocytes (Online Data Supplement). 


\section{Cardiomyocyte purification}

Infant and adult cardiomyocytes were purified by immunomagnetic bead-based depletion of endothelial cells, which was the main contaminating non-myocyte population. After incubation of rat anti-mouse CD31 antibody with sheep anti-rat IgG Dynabeads by overnight rotation at $4^{\circ} \mathrm{C}$, the resulting $\mathrm{Ab}$ conjugated beads (Ab-beads) were stored at $4^{\circ} \mathrm{C}$ (details in Online Table IV). Immediately prior to use, the Ab-beads ( 25 or $50 \mu \mathrm{l}$ per infant and adult sample, respectively) were resuspended and washed three times (1 $\mathrm{mL}$ transfer buffer; buffer composition in Online Table II) using a MagnaRack to remove excess unbound antibody. Enriched cardiomyocyte fractions were resuspended in transfer buffer $(2 \mathrm{~mL})$, added to the washed Ab-beads and incubated on a roller (15 min, RT). Samples were then placed onto the MagnaRack (2 $\mathrm{min}$ ) to separate bead-bound endothelial cells from unbound cardiomyocytes. To ensure complete removal of beads, the supernatant fraction was transferred consecutively into two fresh $2 \mathrm{~mL}$ tubes on the MagnaRack and the supernatants collected into a $15 \mathrm{~mL}$ Falcon tube using uncut transfer pipettes (see Table 1). Two additional gentle bead washes of the original tube ( $2 \mathrm{~mL}$ transfer buffer per wash) were similarly processed to increase cardiomyocyte yield and supernatants were pooled (total 6 $\mathrm{mL}$ ). After gentle resuspension in transfer buffer ( 6 or $8 \mathrm{~mL}$ for infant or adult cardiomyocyte preparations, respectively), cardiomyocytes were counted using a hemocytometer and the proportion of viable, rodshaped cells determined.

Neonatal cardiomyocytes were purified by immunomagnetic separation using the Neonatal Cardiomyocyte Isolation Kit (Miltenyi Biotec), according to manufacturer's instructions. Briefly, cardiac cell suspensions were incubated $\left(15 \mathrm{~min}, 4^{\circ} \mathrm{C}\right)$ with magnetic MicroBeads bound to multiple antibodies (manufacturer's proprietary information) directed at non-myocyte cell surface antigens, passed through a magnetically-charged iron matrix column and the eluate containing cardiomyocytes collected. The column was washed twice with transfer buffer $(1.5 \mathrm{~mL})$ and eluates collected and pooled. After centrifugation ( $300 \mathrm{~g}, 5 \mathrm{~min}$ ), cardiomyocytes were gently resuspended in transfer buffer $(3 \mathrm{~mL})$ using a transfer pipette $(5.8 \mathrm{~mL})$ and counted on a hemocytometer. Cell viability was almost $100 \%$ with round neonatal cardiomyocytes excluding Trypan blue.

Purified cardiomyocyte pellets were stored at $-80^{\circ} \mathrm{C}$ or fixed ( $2 \%$ paraformaldehyde, PFA, 5 min, RT), washed ( $2 \times 10 \mathrm{~mL}$ PBS, $100 \mathrm{~g}-600 \mathrm{~g}, 3 \mathrm{~min}, \mathrm{RT})$ ), and stored in PBS at $4^{\circ} \mathrm{C}$ for subsequent experiments. Overall, the time taken from aortic cannulation to complete purification of cardiomyocytes was approximately one hour for all postnatal ages. 
bioRxiv preprint doi: https://doi.org/10.1101/2021.09.30.462562; this version posted September 30, 2021. The copyright holder for this preprint (which was not certified by peer review) is the author/funder, who has granted bioRxiv a license to display the preprint in perpetuity. It is made available under aCC-BY-NC-ND 4.0 International license.

\section{In situ fixation of cardiac cells}

Cardiac cells were fixed in situ immediately after Langendorff perfusion by flushing the digested heart with $2 \%$ PFA $(2-5 \mathrm{~mL})$ using a $5 \mathrm{~mL}$ syringe. Atria were removed and the heart was submerged in $2 \%$ PFA (5 min). Tissue was disaggregated and passed through an appropriately-sized filter (details in Table 1 and Online Data Supplement). Cell suspensions were fixed further (2\% PFA, 5 min, RT), washed (2x $10 \mathrm{~mL}$ PBS, $100-600 \mathrm{~g}, 3 \mathrm{~min})$, and stored in PBS at $4^{\circ} \mathrm{C}$. Total time taken was $25 \mathrm{~min}$ per heart. 


\section{Results}

\section{Adaption of Langendorff perfusion for neonatal and infant cardiomyocyte isolation}

An overview of the procedure for cardiomyocyte isolation and purification is shown in Figure 3. A critical first step is cannulation of the aorta for Langendorff perfusion and enzymatic digestion of the extracellular matrix prior to tissue disaggregation and cell dissociation. Usually, adult hearts are placed into a petri dish of ice-cold buffer and cannulated ex vivo using a short section of the aorta (transected before or at the aortic $\operatorname{arch})^{9,10}$, however this can be technically challenging and time-consuming, particularly for infant and neonatal hearts. To obviate this, we performed all cannulations in situ with the heart still in the thoracic cavity. Using forceps, the heart was lifted up via the attached thymus and, then, using curved scissors, the entire thoracic aorta was released from its attachment to the spine by careful dissection, pressing the scissors flat along the spine from the aortic arch to the diaphragm, where the aorta was transected. This provided a long length of aorta $(\sim 0.5-1 \mathrm{~cm})$ that was easier to identify and guide onto the cannula. Given the marked differences in aortic diameter and heart size at various postnatal ages (Figure 1C), needles of appropriate sizes were used to cannulate the aortae (Figure 1D and Table 1). With these adaptations, even the small diameter and more fragile infant and neonatal aortae could be cannulated rapidly and with ease ( $3 \mathrm{~min}$ ) under a dissection microscope by drawing the aorta onto a blunted needle. Cannulation of adult hearts took under a minute and a microscope was only required to secure and confirm the correct positioning of the cannula.

Enzymatic digestion was optimized by adjusting the concentration and types of proteolytic enzymes, volume of buffers and perfusate flow rate (Table 1) to obtain high cardiomyocyte yields and viability from hearts of all postnatal ages. Thus, on average, $\sim 1.56 \times 10^{6}$ cardiomyocytes were isolated per P2 heart, $\sim 1.62 \times 10^{6}$ cardiomyocytes per P10 or P13 heart, and $\sim 2.21 \times 10^{6}$ cardiomyocytes per P70 heart (Table 2). The number of rod-shaped infant and adult cardiomyocytes was $~ 72 \%$ (range: $60-90 \%$, Table 2 ), indicating good cell viability; dead cardiomyocytes, in contrast, were round. Surprisingly, the proportion of rodshaped neonatal cardiomyocytes was also high at $~ 53 \%$ (range: 30-90\%, Table 2), which has not been observed previously using the "batch chopping" method that typically yields round cardiomyocytes ${ }^{8}$. Moreover, in contrast to rounded dead infant and adult cardiomyocytes, which do not exclude Trypan blue, almost $100 \%$ of neonatal cardiomyocytes were viable and excluded Trypan blue irrespective of cell shape. We also observed cardiomyocytes isolated from animals at all ages contracting spontaneously. Cardiac cell populations present at the end of the isolation step (immediately after tissue disaggregation and cell filtration) were evaluated by immunocytochemistry using the cardiomyocyte-specific marker, 
cardiac troponin T (cTnT), endothelial cell marker, isolectin B4 (IB4) and the DNA intercalating dye, TOPRO-3 (Figure 4A and Online Figures II-V). Quantification of immunofluorescent staining of cardiac cells fixed in situ showed that cardiomyocytes (TO-PRO- $3^{+} \mathrm{CTnT}^{+}$) comprised 58\%, 36\%, 37\%, and 51\% of nucleated cells in P2, P10, P13, and P70 preparations, respectively, whereas 34\%, 61\%, 50\%, and 39\%, respectively, were endothelial (IB4+) cells (Figure 4B). The "other" TO-PRO- $3^{+}$cells expressed neither cTnT nor IB4.

\section{Infant and adult cardiomyocyte enrichment by differential centrifugation}

For rapid enrichment of infant and adult cardiomyocytes from non-myocytes, such as fibroblasts and endothelial cells, a differential low-speed centrifugation step ( $3 \mathrm{~min}$ ) was performed three times to remove the smaller non-myocytes, which remained in the supernatant fraction, from the larger cardiomyocytes, which pelleted. This step was adapted by increasing the centrifugal force to minimize cardiomyocyte losses of for smaller infant cardiomyocytes. This resulted in the enrichment of P10 cardiomyocytes from 36 to 56\%, P13 cardiomyocytes from $37 \%$ to 52\%, and P70 cardiomyocytes from $51 \%$ to $86 \%$ (Figure 4B). After the enrichment step, total cardiomyocyte yield decreased by 30\% for P10 and P13 and by $\sim 20 \%$ for P70 preparations, but cell viability remained unchanged. Differential centrifugation was not used to enrich neonatal cardiomyocytes as their small size precluded efficient separation from non-myocytes.

\section{Cardiomyocyte purification by immunomagnetic bead-based negative selection}

Following the enrichment step, brightfield and immunofluorescence microscopy revealed endothelial cells were still present as undigested clusters or as strings attached to infant and adult cardiomyocytes (Online Figure I). Endothelial cells were depleted in a purification step using anti-CD31 antibody bound to Dynabeads (Ab-beads). Neonatal cardiomyocytes were purified immediately after the isolation step also by immunomagnetic bead-based negative selection (using the Neonatal Cardiomyocyte Isolation Kit, Miltenyi Biotec). Immunocytochemistry analyses revealed that $96 \%, 96 \%, 93 \%$ and $92 \%$ of nucleated cells in P2, P10, P13 and P70 preparations, respectively, were cardiomyocytes (TO-PRO-3 ${ }^{+} \mathrm{CTnT}^{+}$) (Figure 4B). By contrast, in the Ab-bead bound fraction $69 \%, 90 \%, 85 \%$ and $85 \%$ of nucleated cells in P2, P10, P13 and P70 preparations, respectively, were endothelial cells (IB4 ${ }^{+}$) (Figure 4B). The remaining "other" cells were present in relatively low abundance throughout the procedure and decreased after the enrichment and purification steps. Cardiomyocyte purity assessed by flow cytometry (Figure 4C) demonstrated that after purification the cardiomyocyte population comprised $99 \%, 96 \%$ and $94 \%$ of cells in P2, P10 and P70 
preparations. Cardiomyocyte purity was further validated by qRT-PCR for the expression of cell-typespecific markers that confirmed depletion of endothelial cell (Pecam1 and Vwf) and fibroblast markers (Ddr2 and Col1a1) ${ }^{12}$ after the purification step for all mouse ages (Figure 5A and Online Table VI).

Despite some cell losses during enrichment and purification, the final yield of cardiomyocytes $\left(9 \times 10^{5}\right.$ per P2, P10 and P13 heart, and $1.5 \times 10^{6}$ cardiomyocytes per P70 heart; Table 2) remained high, providing sufficient input material for molecular studies (DNA, RNA, protein) from individual hearts (Table 3). The average RIN score was $~ 8.75$ across all ages, indicating high quality RNA. Importantly, the proportion of spindle-shaped and viable neonatal cardiomyocytes was unaltered after purification, and cell viability (rod-shaped) was either unaltered or only slightly reduced after purification of infant and adult cardiomyocytes. Thus, the yield, purity and quality of cardiomyocytes after the final purification step was high (Figure 5B).

\section{In situ fixation of cardiomyocytes prior to tissue disaggregation}

To evaluate intrinsic cardiomyocyte morphology, cardiomyocytes were fixed in situ. This revealed that almost all cells were rod-shaped ( 94\%), including neonatal cardiomyocytes that were more spindleshaped. Thus, in situ fixation resulted in an increase in the proportion of rod-shaped cells by $43 \%, \sim 16 \%$ and $\sim 30 \%$ compared to cardiomyocytes fixed post-isolation at neonatal, infant and adult ages, respectively (Figure 6A). Perfusion fixation even allowed spindle-shaped neonatal cardiomyocytes to be captured undergoing cytokinesis, as evidenced by Aurora B kinase staining of the midbody (Figure 6D).

\section{Morphological characterization of postnatal CM maturation}

Characterization of in situ fixed cardiomyocytes revealed that cardiomyocyte cytoarchitecture changes considerably from small spindle-shaped cells at P2 to highly irregular large rod-shaped adult cells with jagged edges at the intercalated discs (Figure 6C). The average cell area of in situ-fixed cardiomyocytes increased by 2.3-, 2.8- and 9.6-fold from P2 to P10, P13 and P70, respectively (Table 3 \& Figure 6B). Cardiomyocyte area correlated closely with heart weight at each age, indicating close tracking of cardiomyocyte enlargement with overall cardiac growth (Figure 6E). Changes in nucleation state were also readily apparent: $93 \%$ of P2 cardiomyocytes being mononucleated, whereas the majority (73-84\%) were binucleated by P10-13 and thereafter (Figure 6B).

\section{RNA-sequencing of neonatal cardiomyocytes from individual hearts}


Cardiomyocytes were purified from one P2 male and female heart per litter of 6-8 C57BL/6J mouse pups ( $n=4$ litters) and RNA-sequencing was performed using poly(A)-enriched RNA extracted from each individual heart (Figure 7A). As well as RNA, DNA was simultaneously extracted from the same cardiomyocyte preparation to verify the sex of mouse pup by PCR amplification of the sex-determining region (SRY on Chr Y, Online Figure VI). Body weights were similar between litters and sexes (Figure 7B). Transcriptome analysis revealed a total of 12,854 genes (> $1 \mathrm{cpm}$ in 4 samples) and that unsupervised clustering of gene expression profiles grouped neonatal cardiomyocytes by litter rather than by sex (Figure 7C). Differential expression analysis revealed only nine differentially expressed genes between sexes (DEGs, FDR<0.005; Figure 7D \& E), all located on the sex chromosomes (Chr Y: Gm29650, Eif2s3y, Ddx3y, Uty, Kdm5d; Chr X: Kdm5c, Kdm6a, Xist, Eif2s3x). 


\section{Discussion}

Current methods used to isolate cardiomyocytes are age-dependent and involve either crude "batch chopping" of pooled neonatal hearts or Langendorff retrograde perfusion of an individual adult heart. These methods differ considerably with respect to processing times, tissue digestion conditions and number of hearts used per isolation. Moreover, incorporation of cell culture methods for cardiomyocyte purification requires long incubations, which inevitably leads to cellular and molecular changes. To this end, we have developed a standardized method for the isolation of cardiomyocytes from individual hearts of any age. This involves in situ cannulation of neonatal and infant aortae followed by optimized tissue digestion using Langendorff retrograde perfusion. Importantly, we then added a short and simple immunomagnetic cell separation step to effectively remove non-myocytes allowing us to obtain highly purified viable cardiomyocytes ( 94\%) in high yield that can be used to conduct molecular studies. We also present an in situ fixation method to preserve cardiomyocyte cytoarchitecture for accurate assessment of cell morphology and for immunocytochemistry experiments.

Our in situ cannulation method is a significant advance that enables individual neonatal and infant hearts to be Langendorff-perfused for cardiomyocyte isolation and builds upon our previous work ${ }^{13}$. To the best of our knowledge, only one other group has isolated neonatal cardiomyocytes by Langendorff retrograde perfusion ${ }^{14}$, and this involved complex ex vivo microscopic manipulations to fix a glass cannula to the ascending aorta with an epoxy. More recently, these investigators applied antegrade perfusion via a needle inserted into the apex of the left ventricle and clamped the aorta ${ }^{15}$ to overcome the technical difficulties associated with cannulating the aorta of younger mice. This method of antegrade perfusion was originally developed to isolate left ventricular adult cardiomyocytes ${ }^{16}$. For Langendorff perfusion, typically the adult heart is excised and placed into a petri dish of ice-cold buffer before aortic cannulation ex vivo ${ }^{9,10,17}$. This is technically challenging for adult hearts, but particularly so for those of neonates, as it involves identification of the small opening of the relatively short aortic stump resulting from transection at the aortic arch that is often hidden by connective tissues, which makes cannulation difficult and time consuming. To obviate this problem, we transected the aorta in situ at the level of the diaphragm, which provides a longer length of vessel that can be readily cannulated and then mounted onto the perfusion rig. This easier technique of cannulation improves accessibility for those wanting to use a Langendorff apparatus, especially for younger hearts, and is useful not only for cardiomyocyte isolations but also for working heart models, as recently described for $\mathrm{P} 10$ hearts $^{18}$. 
A key advance in the Langendorff perfusion method described here was the optimization of tissue digestion conditions, including flow rate, concentrations of proteolytic enzymes, and volumes of perfusion and digestion buffers, to isolate cardiomyocytes from hearts of all ages in a comparable time ( $13 \mathrm{~min}$ ). An important measure of successful cardiomyocyte isolation is yield, and yet, it is not widely reported. One commercial neonatal cardiomyocyte isolation kit (Thermo Scientific Pierce Primary Cardiomyocyte Isolation Kit) recommends the use of $\sim 10-15$ murine hearts to yield $\sim 2$ million cardiomyocytes per $100 \mathrm{mg}$ of tissue. Yields from our protocol are $\sim 11$-fold higher, i.e., 1.56 million ventricular cardiomyocytes per neonatal heart (average weight: $~ 7 \mathrm{mg}$ ), which equates to 22 million cardiomyocytes per $100 \mathrm{mg}$ of tissue. Others using the traditional "batch chopping" method have reported an extrapolated yield of $0.59 \times 10^{6}$ per heart, which is $\sim 2.6$-fold lower than the yield we achieved. Although an improved version of the "batch chopping" method provides yields similar to ours $\left(\sim 1.3 \times 10^{6}\right)$, it still requires multiple neonatal hearts and takes $>12-16 \mathrm{~h}$ per isolation ${ }^{19}$. Importantly, the structural integrity of neonatal cardiomyocytes ( $53 \%$ rod-shaped) and viability of infant cardiomyocytes ( $70 \%$ rod-shaped) that our method provides are higher than those reported previously. Our yield of 2.2 million ventricular cardiomyocytes with a viability of $\sim 72 \%$ from adult hearts is comparable to others using Langendorff perfusion methods ${ }^{15,20,21}$. Thus, the combination of in situ cannulation and Langendorff digestion can be used to isolate cardiomyocytes in high quality and yield, not only from adult hearts, but also from individual neonatal and infant hearts, i.e., without using age-dependent procedures or pooling of hearts; the latter having the advantage of reducing animal usage.

Although our study was not designed to specifically evaluate cell type populations in the heart, it is of interest that in agreement with the recent study of Pinto et al. ${ }^{22}$, but in contrast to previous reports ${ }^{23,24}$, we found that endothelial cells are the predominant non-myocyte population in adult hearts; a finding we also observed in neonatal and infant hearts (Fig 4B). Non-myocyte populations were partially removed by differential centrifugation to enrich the adult cardiomyocyte population ${ }^{10}$ and this step was adapted to enrich infant cardiomyocytes. Nevertheless, significant endothelial cell contamination remained - the extent of which varied with different batches of digestion enzymes. For this reason, we employed immunomagnetic cell separation to negatively select contaminating endothelial cells and, thus, to additionally purify cardiomyocytes. This resulted in a consistently pure population ( $94 \%$ ), as confirmed by immunocytochemistry and further validated by flow cytometry and qRT-PCR. Negative selection, by use of a kit targeting multiple non-myocytes, was also effective in purifying neonatal cardiomyocytes. This 
final crucial step of cardiomyocyte purification can be performed rapidly ( $22 \mathrm{~min}$ ) at the lab bench for hearts of all ages. Immunomagnetic cell isolation is clearly an improvement on traditional cell culture methods when used to purify cardiomyocytes, which involve longer incubation times that can lead to cellular and molecular phenotypic changes ${ }^{6}$. In contrast to cardiomyocytes, cardiac endothelial cells have been isolated by incubation of chopped myocardium with collagenase $A^{25}$ or collagenase IV (similar to collagenase D) and dispase $\mathrm{II}^{22}$ for 45-60 min to digest the extracellular matrix. However, this compromises the quality and viability of cardiomyocytes. Since enzymatic tissue digestion using Langendorff retrograde perfusion is a gentler process compared to chopping tissues, it may be possible in future studies to further develop the protocol used here to enable the isolation not only of cardiomyocytes, but also all cardiac cell types by incorporating other extracellular matrix-targeting enzymes into the digestion buffer.

As shown here, cardiomyocytes fixed in situ retained cell integrity- their cytoarchitecture closely resembling that seen in vivo, with most ( $94 \%)$ being either rod- or spindle-shaped. The spindle shape of neonatal cardiomyocytes is consistent with them already being contractile in utero $^{26,27}$; the heart beginning to beat very early in fetal development. Moreover, the finding of intact spindle- or rod-shaped cells suggests that the process of Langendorff tissue digestion itself is gentle and not responsible for loss of cell structure or viability, which, rather, occurs as a result of subsequent cell dissociation steps. The use of isolated cardiomyocytes for morphological characterization obviates inaccuracies inherent in evaluation of cardiomyocyte size, nucleation state and cell population types from tissue sections (even using thick sections) ${ }^{22,28-30}$. Such inaccuracies are due to cardiomyocyte overlap, their large size, particularly adult cells, and their irregular shape, which we found can vary by up to a third in size in cells from hearts of all ages, all of which contribute to difficulties in the discrimination of cardiomyocyte boundaries in tissue sections. Hence, we used in situ fixed cardiomyocytes that are mostly intact, unlike those fixed only after isolation, for robust evaluations of cell area and binucleation. Cardiomyocyte cell size, determined by planimetry of cell area, which we have used previously for accurate quantitation ${ }^{31,32}$, demonstrated that throughout postnatal development cell size increases commensurately with cardiac growth (heart weight). Our estimate of binucleation index in infant cardiomyocytes was close to that in adult cells (85\%) by P13 (81\%), albeit lower than previous assessments of $98 \%$ and $95 \%$ for $\mathrm{P} 8^{33}$ and $\mathrm{P} 10^{23}$ cells, respectively. This may reflect differences in mouse strain or litter size, which, in turn, influence the rate of cardiac growth. Importantly, in situ fixation captured spindle-shaped neonatal cells undergoing cytokinesis; a cytoarchitecture that has only been observed previously in tissue sections ${ }^{34}$ and cell culture. Thus, in situ fixation is a valuable method for studying cardiomyocyte morphology as well as for the 
detection and spatial localization of proteins of interest, such as Aurora B kinase, to better appreciate cell function.

An understanding of the complex process of cardiac development requires sufficient material (DNA, RNA, and protein) from freshly purified cardiomyocytes for omics-based experiments (genomic, epigenomic, transcriptomic, and proteomic studies) and for biochemical assays, such as PCR, qRT-PCR, immunocytochemistry and Western blot analyses. As we show here, our cardiomyocyte purification procedure allowed, for the first time, RNA-seq studies to be undertaken with individual neonatal hearts. These analyses showed that gene expression clustered predominantly on the basis of biological differences between litters, albeit that this finding needs to be validated in future studies using a larger number of replicates. There was also evidence of sexual dimorphism, with nine DEGs (located on sex chromosomes). Xist, a long non-coding RNA, required for $\mathrm{X}$ inactivation, showed the highest expression and fold-change $(>1000)$ in females and can, thus, be used for sex identification. Some of the DEGs we observed have also been reported in single nuclei studies of adult human cardiomyocyte nuclei ${ }^{35}$, and in single cell studies of other cardiac cell types from the adult mouse ${ }^{36}$ or human ${ }^{35}$ heart. Single cell studies provide information on the cellular heterogeneity of gene expression, such studies of cardiomyocytes are generally limited to the evaluation of nuclear transcripts because their larger cell size is incompatible with high-throughput droplet sequencing technologies, although lower throughput sequencing platforms ${ }^{37}$ have allowed capture of both nuclear and cytoplasmic transcripts. Moreover, in contrast to single cell transcriptomic studies, cardiomyocytes purified using the method we developed here can be used in a range of assays for cell-type specific investigations, as well as for the evaluation of younger hearts for individual genetic, therapeutic, surgical, age, sex, and biological differences.

In summary, we have established a rapid procedure to isolate and purify cardiomyocytes in high yield, viability and purity from murine hearts at any postnatal age. This method enables study of age-related changes in cardiomyocytes and analysis of individual biological replicates, even in neonatal mice. Moreover, Langendorff perfusion combined with in situ fixation allows preservation of the native cytoarchitecture for accurate assessment of cell morphology and proliferative status. 


\section{Acknowledgements}

We gratefully acknowledge the Micro Imaging Facility, The Victor Chang Cardiac Research Institute Innovation Centre for immunofluorescence imaging and The Garvan-Weizmann Centre for Cellular Genomics for assistance with flow cytometry studies. We also acknowledge the services and facilities of Australian Genome Research Facility (AGRF) for generating RNA-Sequencing data.

\section{Sources of Funding}

This work was supported in part by grants from the National Health and Medical Research Council of Australia [to RMG, \#573732 and \#1074386], the Heart Foundation of Australia grant [to RMG, ML, SEI, G10S 5148], and Future Leader Fellowship [to NJS, \#101153], the RT Hall Estate [to RMG], the Australian Research Council Special Research Initiative in Stem Cell Science [to RMG, SR110001002], and the Leducq Transatlantic Network of Excellence in Cardiovascular Research [to RMG, AH].

\section{Disclosures}

None

\section{Supplemental Material}

Expanded Materials \& Methods

Online Figures I-VI

Online Tables I-VI

References 9, 10, 13, 32, 38-42 


\section{References}

1. Porrello ER, Widdop RE, Delbridge LMD. Early origins of cardiac hypertrophy: Does cardiomyocyte attrition programme for pathological "catch-up" growth of the heart? Clin. Exp. Pharmacol. Physiol. 2008;35(11):1358-1364. doi:10.1111/j.1440-1681.2008.05036.x

2. Tutarel $\mathrm{O}$. Acquired heart conditions in adults with congenital heart disease: a growing problem. Heart. 2014;100(17):1317-1321. doi:10.1136/heartjnl-2014-305575

3. Marian AJ. Congenital Heart Disease: The Remarkable Journey from the "Post-Mortem Room" to Adult Clinics. Circ. Res. 2017;120(6):895-897. doi:10.1161/CIRCRESAHA.117.310830

4. Harary I, Farley B. In vitro Studies of Single Isolated Beating Heart Cells. Science (80-. ). 1960;131(3414):1674-1675. doi:10.1126/science.131.3414.1674

5. Kono T. Roles of collagenases and other proteolytic enzymes in the dispersal of animal tissues. Biochim. Biophys. Acta - Enzymol. 1969;178(2):397-400. doi:10.1016/0005-2744(69)90410-0

6. Louch WE, Sheehan KA, Wolska BM. Methods in cardiomyocyte isolation, culture, and gene transfer. J. Mol. Cell. Cardiol. 2011;51(3):288-298. doi:10.1016/j.yjmcc.2011.06.012

7. Cao T, Liccardo D, LaCanna R, Zhang X, Lu R, Finck BN, Leigh T, Chen X, Drosatos K, Tian Y. Fatty Acid Oxidation Promotes Cardiomyocyte Proliferation Rate but Does Not Change Cardiomyocyte Number in Infant Mice. Front. Cell Dev. Biol. 2019;7(MAR):1-15. doi:10.3389/fcell.2019.00042

8. Ehler E, Moore-Morris T, Lange S. Isolation and Culture of Neonatal Mouse Cardiomyocytes. J. Vis. Exp. 2013;15(79):1-10. doi:10.3791/50154

9. Liao R, Jain M. Isolation, culture, and functional analysis of adult mouse cardiomyocytes. Vasc. Biol. Protoc. 2007;139:251-262. doi:1-59745-571-7:251 [pii]

10. O'Connell TD, Rodrigo MC, Simpson PC. Isolation and culture of adult mouse cardiac myocytes. Methods Mol. Biol. 2007;357(7):271-296. doi:10.1385/1-59745-214-9:271

11. Chlopčíková Š, Psotová J, Miketová P. NEONATAL RAT CARDIOMYOCYTES - A MODEL FOR THE STUDY OF MORPHOLOGICAL, BIOCHEMICAL AND ELECTROPHYSIOLOGICAL CHARACTERISTICS OF THE HEART. Biomed. Pap. 2001;145(2):49-55. doi:10.5507/bp.2001.011

12. Travers JG, Kamal FA, Robbins J, Yutzey KE, Blaxall BC. Cardiac fibrosis: The fibroblast awakens. Circ. Res. 2016;118(6):1021-1040. doi:10.1161/CIRCRESAHA.115.306565

13. Naqvi N, Li M, Calvert JW, Tejada T, Lambert JP, Wu J, Kesteven SH, Holman SR, Matsuda T, Lovelock JD, Howard WW, lismaa SE, Chan AY, Crawford BH, Wagner MB, et al. A proliferative burst during preadolescence establishes the final cardiomyocyte number. Cell. 2014;157(4):795-807. doi:10.1016/j.cell.2014.03.035 
14. Hoshino S, Omatsu-Kanbe M, Nakagawa M, Matsuura H. Postnatal developmental decline in IK1 in mouse ventricular myocytes isolated by the Langendorff perfusion method: comparison with the chunk method. Pflugers Arch. Eur. J. Physiol. 2012;463(5):649-668. doi:10.1007/s00424-012-10840

15. Omatsu-Kanbe M, Yoshioka K, Fukunaga R, Sagawa H, Matsuura H. A simple antegrade perfusion method for isolating viable single cardiomyocytes from neonatal to aged mice. Physiol. Rep. 2018;6(9):1-9. doi:10.14814/phy2.13688

16. Ackers-Johnson M, Li PY, Holmes AP, O’Brien SM, Pavlovic D, Foo RS. A Simplified, LangendorffFree Method for Concomitant Isolation of Viable Cardiac Myocytes and Nonmyocytes from the Adult Mouse Heart. Circ. Res. 2016;119(8):909-920. doi:10.1161/CIRCRESAHA.116.309202

17. Plačkić J, Kockskämper J. Isolation of Atrial and Ventricular Cardiomyocytes for In Vitro Studies.; 2018. doi:10.1007/978-1-4939-8597-5_3.

18. Barajas M, Yim PD, Gallos G, Levy RJ. An isolated retrograde-perfused newborn mouse heart preparation. MethodsX. 2020;7:101058. doi:10.1016/j.mex.2020.101058

19. Li C, Rong X, Qin J, Wang S. An improved two-step method for extraction and purification of primary cardiomyocytes from neonatal mice. J. Pharmacol. Toxicol. Methods. 2020;104(June):106887. doi:10.1016/j.vascn.2020.106887

20. Limana F, Urbanek K, Chimenti S, Quaini F, Leri A, Kajstura J, Nadal-Ginard B, Izumo S, Anversa P. Bcl-2 overexpression promotes myocyte proliferation. Proc. Natl. Acad. Sci. U. S. A. 2002;99(9):6257-6262. doi:10.1073/pnas.092672899

21. Shioya T. A simple technique for isolating healthy heart cells from mouse models. J. Physiol. Sci. 2007;57(6):327-335. doi:10.2170/physiolsci.RP010107

22. Pinto AR, Ilinykh A, Ivey MJ, Kuwabara JT, D'antoni ML, Debuque R, Chandran A, Wang L, Arora K, Rosenthal NA, Tallquist MD. Revisiting cardiac cellular composition. Circ. Res. 2016;118(3):400409. doi:10.1161/CIRCRESAHA.115.307778

23. Soonpaa MH, Kim KK, Pajak L, Franklin M, Field L. Cardiomyocyte DNA synthesis and binucleation during murine development. Am. J. Physiol. Circ. Physiol. 1996;271(5):H2183-H2189. doi:10.1152/ajpheart.1996.271.5.H2183

24. Banerjee I, Fuseler JW, Price RL, Borg TK, Baudino TA. Determination of cell types and numbers during cardiac development in the neonatal and adult rat and mouse. AJP Hear. Circ. Physiol. 2007;293(3):H1883-H1891. doi:10.1152/ajpheart.00514.2007

25. Jelonek K, Walaszczyk A, Gabryś D, Pietrowska M, Kanthou C, Widłak P. Cardiac endothelial cells 
isolated from mouse heart - A novel model for radiobiology. Acta Biochim. Pol. 2011;58(3):397404. doi:10.18388/abp.2011_2253

26. Hirschy A, Schatzmann F, Ehler E, Perriard JC. Establishment of cardiac cytoarchitecture in the developing mouse heart. Dev. Biol. 2006;289(2):430-441. doi:10.1016/j.ydbio.2005.10.046

27. Risebro CA, Searles RG, Melville AAD, Ehler E, Jina N, Shah S, Pallas J, Hubank M, Dillard M, Harvey NL, Schwartz RJ, Chien KR, Oliver G, Riley PR. Prox1 maintains muscle structure and growth in the developing heart. Development. 2009;136(3):495-505. doi:10.1242/dev.030007

28. Roth GM, Bader DM, Bader DM, Pfaltzgraff ER. Isolation and physiological analysis of mouse cardiomyocytes. J. Vis. Exp. 2014;(91):1-9. doi:10.3791/51109

29. Raulf A, Horder H, Tarnawski L, Geisen C, Ottersbach A, Röll W, Jovinge S, Fleischmann BK, Hesse M. Transgenic systems for unequivocal identification of cardiac myocyte nuclei and analysis of cardiomyocyte cell cycle status. Basic Res. Cardiol. 2015;110(3). doi:10.1007/s00395-015-0489-2

30. Bensley JG, De Matteo R, Harding R, Black MJ. Three-dimensional direct measurement of cardiomyocyte volume, nuclearity, and ploidy in thick histological sections. Sci. Rep. 2016;6(March):1-10. doi:10.1038/srep23756

31. lismaa SE, Li M, Kesteven S, Wu J, Chan AY, Holman SR, Calvert JW, Haq AU, Nicks AM, Naqvi N, Husain A, Feneley MP, Graham RM. Cardiac hypertrophy limits infarct expansion after myocardial infarction in mice. Sci. Rep. 2018;8(1):1-13. doi:10.1038/s41598-018-24525-6

32. Nicks AM, Kesteven SH, Li M, Wu J, Chan AY, Naqvi N, Husain A, Feneley MP, Smith NJ, lismaa SE, Graham RM. Pressure overload by suprarenal aortic constriction in mice leads to left ventricular hypertrophy without c-Kit expression in cardiomyocytes. Sci. Rep. 2020;10(1):1-12. doi:10.1038/s41598-020-72273-3

33. Walsh S, Pontén A, Fleischmann BK, Jovinge S. Cardiomyocyte cell cycle control and growth estimation in vivo-An analysis based on cardiomyocyte nuclei. Cardiovasc. Res. 2010;86(3):365373. doi:10.1093/cvr/cvq005

34. Hesse M, Doengi M, Becker A, Kimura K, Voeltz N, Stein V, Fleischmann BK. Midbody Positioning and Distance Between Daughter Nuclei Enable Unequivocal Identification of Cardiomyocyte Cell Division in Mice. Circ. Res. 2018;123(9):1039-1052. doi:10.1161/CIRCRESAHA.118.312792

35. Tucker NR, Chaffin M, Fleming SJ, Hall AW, Parsons VA, Bedi KC, Akkad AD, Herndon CN, Arduini A, Papangeli I, Roselli C, Aguet F, Choi SH, Ardlie KG, Babadi M, et al. Transcriptional and Cellular Diversity of the Human Heart. Circulation. 2020;142(5):466-482. doi:10.1161/CIRCULATIONAHA.119.045401 
36. Skelly DA, Squiers GT, McLellan MA, Bolisetty MT, Robson P, Rosenthal NA, Pinto AR. Single-Cell Transcriptional Profiling Reveals Cellular Diversity and Intercommunication in the Mouse Heart. Cell Rep. 2018;22(3):600-610. doi:10.1016/j.celrep.2017.12.072

37. Yekelchyk M, Guenther S, Preussner J, Braun T. Mono- and multi-nucleated ventricular cardiomyocytes constitute a transcriptionally homogenous cell population. Basic Res. Cardiol. 2019;114(5):1-13. doi:10.1007/s00395-019-0744-z

38. Cheng R, Zhang F, Li M, Wo X, Su YW, Wang W. Influence of Fixation and Permeabilization on the Mass Density of Single Cells: A Surface Plasmon Resonance Imaging Study. Front. Chem. 2019;7(August):1-7. doi:10.3389/fchem.2019.00588

39. Sturm KS, Berger CN, Zhou SX, Dunwoodie SL, Tan SS, Tam PPL. Unrestricted lineage differentiation of parthenogenetic ES cells. Dev. Genes Evol. 1997;206(6):377-388. doi:10.1007/s004270050067

40. Bolger AM, Lohse M, Usadel B. Trimmomatic: A flexible trimmer for Illumina sequence data. Bioinformatics. 2014;30(15):2114-2120. doi:10.1093/bioinformatics/btu170

41. Veeneman BA, Shukla S, Dhanasekaran SM, Chinnaiyan AM, Nesvizhskii Al. Two-pass alignment improves novel splice junction quantification. Bioinformatics. 2016;32(1):43-49. doi:10.1093/bioinformatics/btv642

42. Robinson MD, McCarthy DJ, Smyth GK. edgeR: A Bioconductor package for differential expression analysis of digital gene expression data. Bioinformatics. 2009;26(1):139-140. doi:10.1093/bioinformatics/btp616 


\section{Figures}

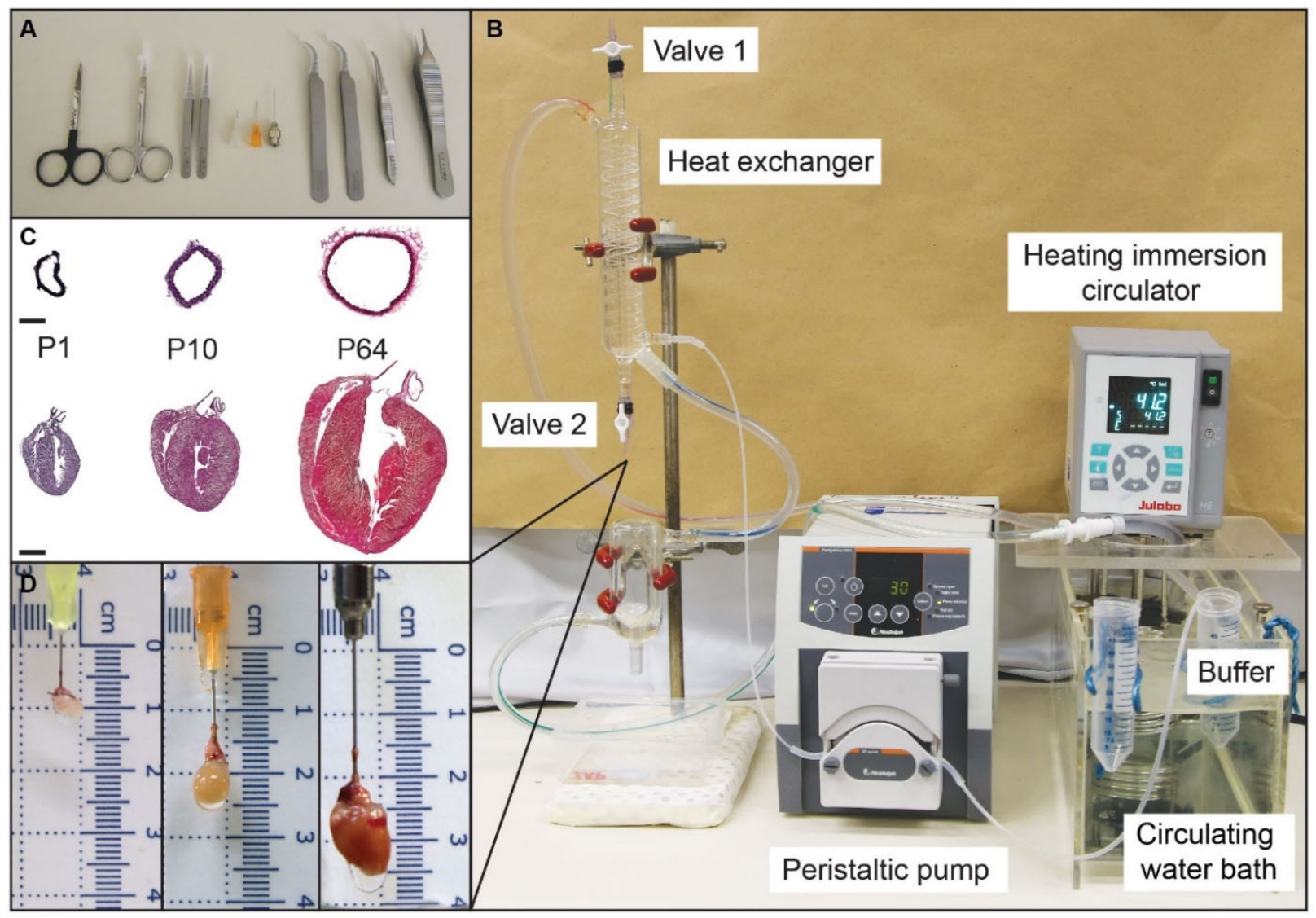

Figure 1: Apparatus used for cannulation of aortae and Langendorff perfusion of murine hearts

A, microsurgical tools used to cannulate murine hearts, from left to right: tough cut straight sharp scissors, fine sharp scissors, mini forceps $\times 2$, blunted $30 \mathrm{G}$ and $25 \mathrm{G}$ needles, and $24 \mathrm{G}$ gavage needle, curved forceps $x 2$, and curved and straight serrated forceps. B, Langendorff apparatus consisting of a heating immersion circulator to control water bath temperature, which is adjusted to maintain the perfusate at $37^{\circ} \mathrm{C}$. The heated water is circulated through the insulating jacket of the heat exchanger. Immediately before mounting the heart, a pressure gradient is created to allow perfusate to flow by closing valve 1 (in the horizontal position), opening valve 2 (in the vertical position), and turning on the peristaltic pump (John Morris Group). The pump sends buffers through the tubing and coil inside of the heat exchanger, allowing tissue perfusion at a regulated flow rate and temperature. The water-jacketed insulating organ bath is moved upwards to surround the heart and maintain a warm environment. C, H \& E stained (DNA, blue; and cell cytoplasm, red) transverse sections of aortae at the level of the diaphragm (scale bar is 200 $\mu \mathrm{m}$ ), and sagittal sections of hearts (scale bar is $1 \mathrm{~mm}$ ) from neonatal (P1), infant (P10) and adult (P64) 
bioRxiv preprint doi: https://doi.org/10.1101/2021.09.30.462562; this version posted September 30, 2021. The copyright holder for this preprint (which was not certified by peer review) is the author/funder, who has granted bioRxiv a license to display the preprint in perpetuity. It is made available under aCC-BY-NC-ND 4.0 International license.

mice. D, Cannulated P1, P10 and P70 (left to right) murine hearts (sizes indicated by the scales in the background) mounted onto the Langendorff apparatus. 

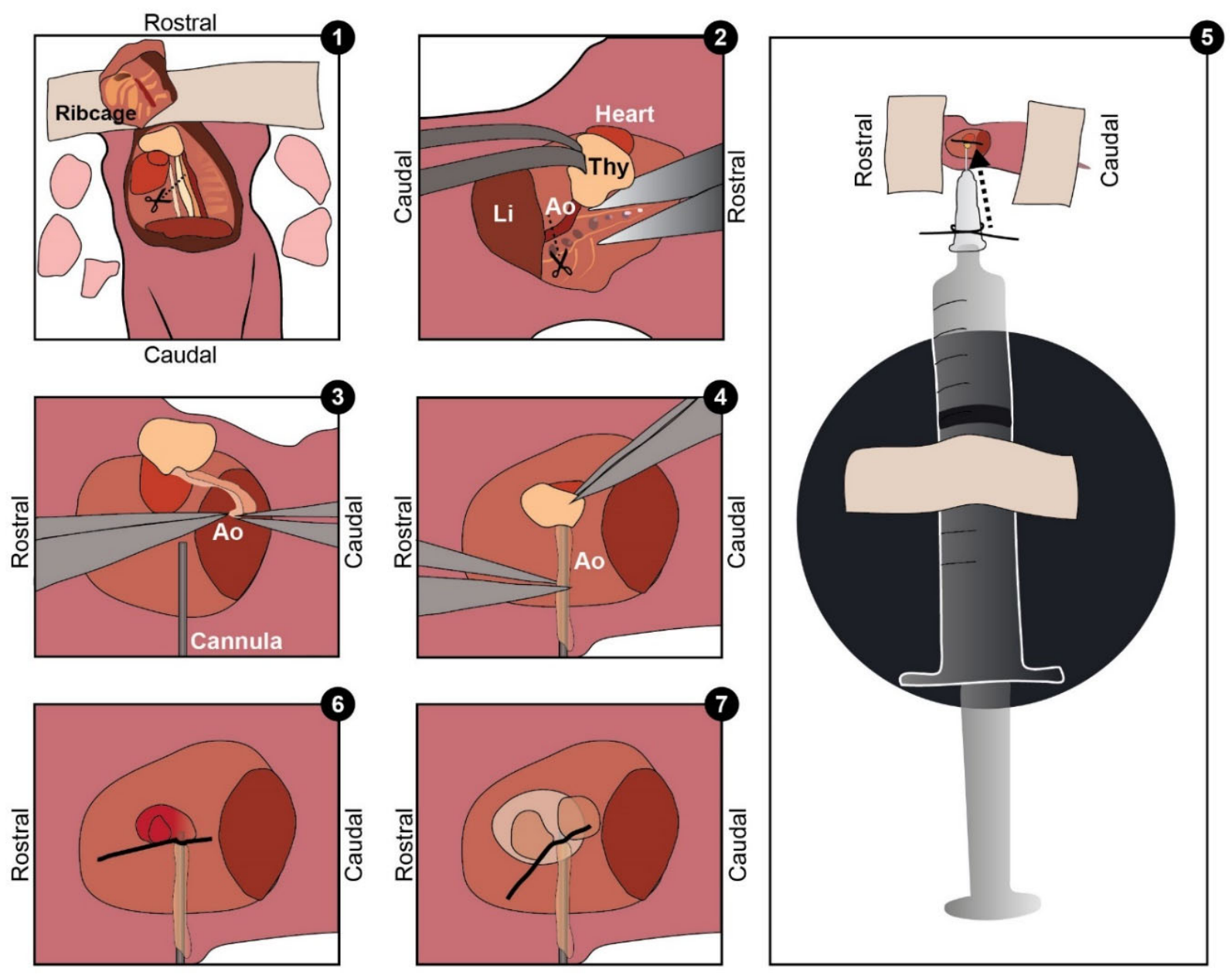

Figure 2: In situ cannulation of the neonatal murine heart

Step 1: The ribcage of a neonatal mouse (P2) is dissected open, the five lung lobes removed and the inferior vena cava and oesophagus transected. Step 2: The operating board was rotated $90^{\circ}$ (right-handed operator; liver [Li] to the left) and fine forceps used to grip and elevate the thymus (Thy) attached to the heart, and then fine curved scissors used to dissect under the aorta (Ao) to release it from the spine. The aorta is then transected at the level of the diaphragm. Step 3 and 4: The operating board was rotated another $180^{\circ}$ and the aorta (now drained of blood) is cannulated in situ by gripping the edges of the transected vessel with fine forceps and pulling it onto a cannula (blunted $30 \mathrm{G}$ needle) attached to a syringe. Step 5: A silk suture that had been loosely tied around the base of the cannula prior to cannulation, is re-positioned so that it sits around the cannulated aorta at a level between the thymus and atria, and then tightened into a double knot. The thymus is then removed. The set-up of the cannula attached to the syringe $(10 \mathrm{~mL})$ is shown relative to the size of a P2 mouse pup. Step 6: the heart is immediately mounted onto the Langendorff rig, or, step 7: when practising cannulations, instead of mounting the heart on the rig, the heart is flushed with perfusion buffer using the syringe. Correct 
bioRxiv preprint doi: https://doi.org/10.1101/2021.09.30.462562; this version posted September 30, 2021. The copyright holder for this preprint (which was not certified by peer review) is the author/funder, who has granted bioRxiv a license to display the preprint in perpetuity. It is made available under aCC-BY-NC-ND 4.0 International license.

placement of the cannula is evident by blanching and expansion of the heart as it is perfused with buffer

from the syringe. Note: neonates and infants have a smaller, shorter, and more delicate aorta that is susceptible to breakage. 
1. Animal sacrifice and in situ cannulation of the heart

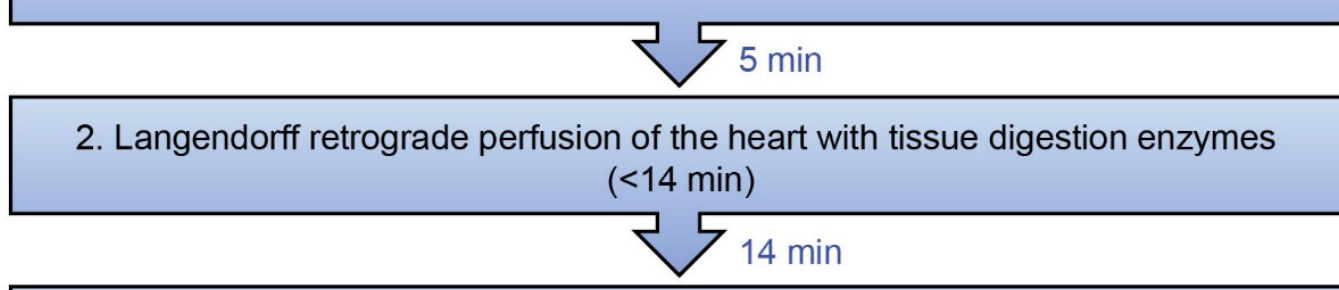

3. Cell isolation: cardiac ventricles teased apart into a cell suspension that is filtered

$5 \min$

4. Cardiomyocyte enrichment: $3 x$ low-speed differential centrifugations

$12 \min$

5. Cardiomyocyte purification: 15 min incubation of cells with Ab-beads to remove bound non-myocytes and collect unbound cardiomyocytes

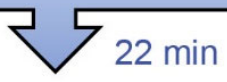

Figure 3: Overview of the cardiomyocyte isolation and purification procedure

Flow diagram outlining the isolation and purification procedure $(<1 \mathrm{hr})$. For in situ fixation of cardiac cells, the heart is perfused with paraformaldehyde immediately after step 2 . The cardiomyocyte enrichment (step 4) is omitted for neonatal cardiac cells. See Methods for further details. 
A

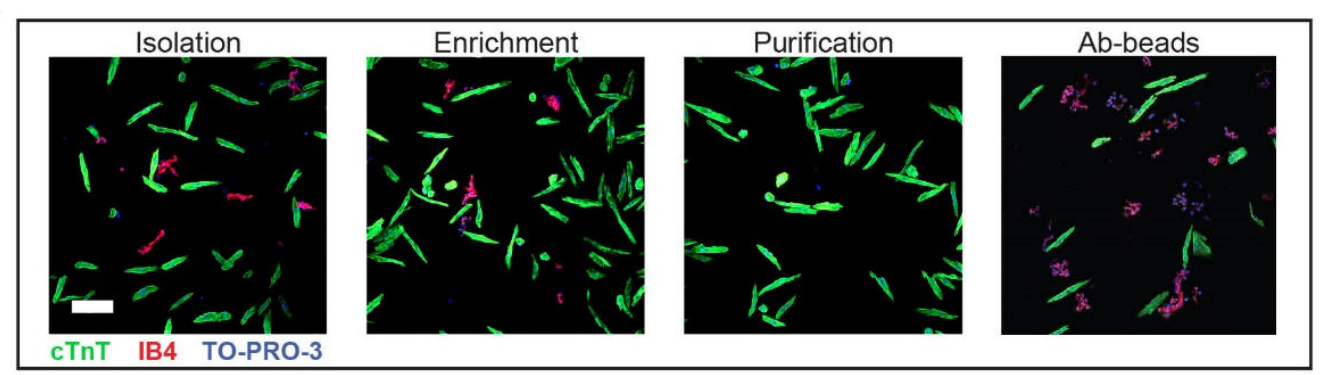

B
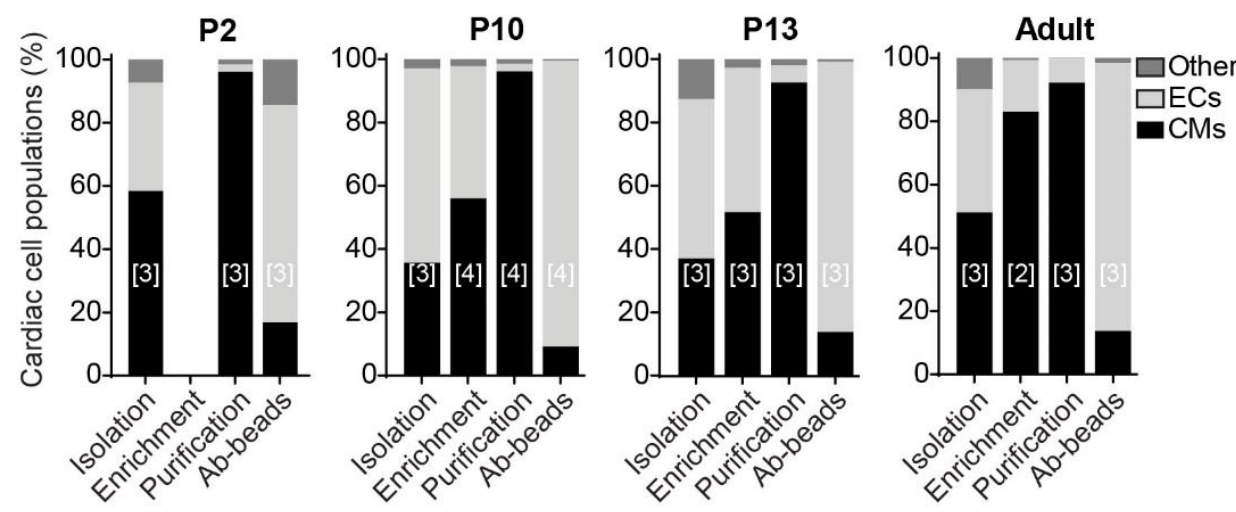

C

P2
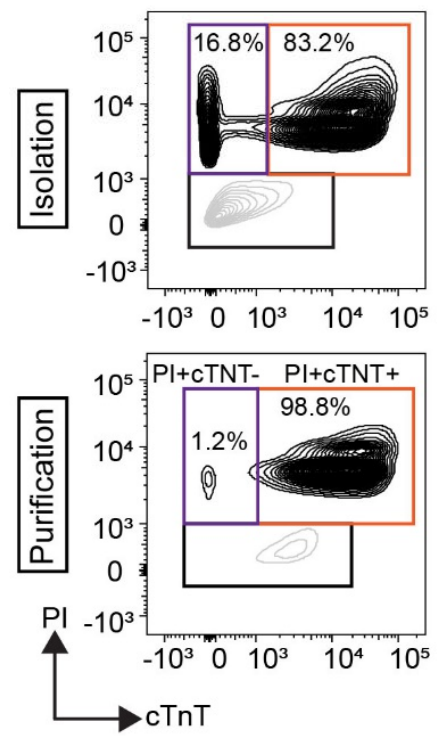

P10
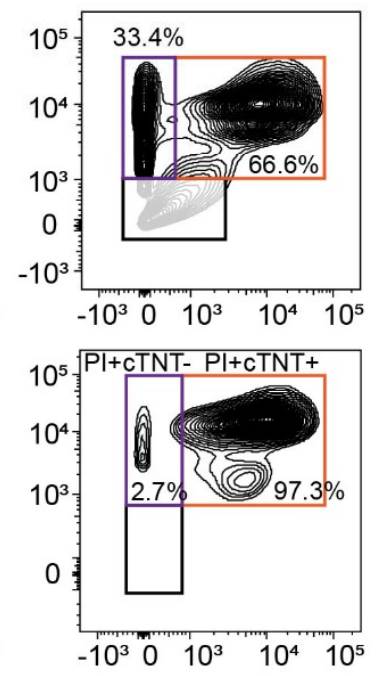

Adult
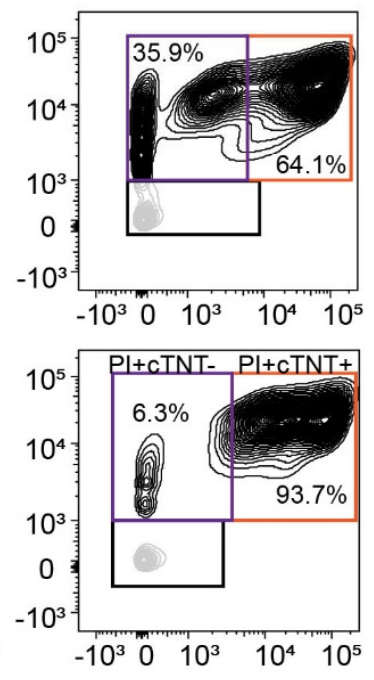

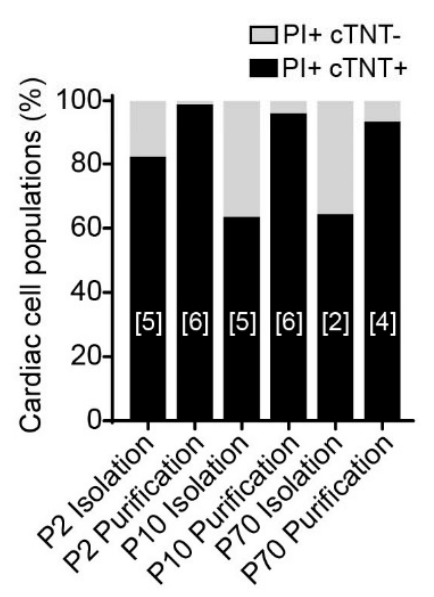

Figure 4: Cardiomyocyte purity assessed by immunocytochemistry and flow cytometry

A, Representative immunofluorescence images of C57BL/6J P10 murine cardiac cells stained to identify nucleated (DNA, TO-PRO-3, blue) cardiomyocytes (cardiac troponin T, cTnT, green) and endothelial cells (isolectin B4, IB4, red) following cardiomyocyte isolation, enrichment and purification steps, including the CD31 Ab-bead bound fraction. Scale bar is $100 \mu \mathrm{m}$. B, Quantification from immunocytochemistry of cardiac cell types after each step of isolation and purification from C57BL/6J P2 ( $n=3, \sim 2000$ cells/n), P10 ( $n=3-4$, $\sim 1500$ cells/n), P13 ( $n=3, \sim 1500$ cells/n), or adult ( $n=3, \sim 1500$ cells/n) hearts (see representative images 
bioRxiv preprint doi: https://doi.org/10.1101/2021.09.30.462562; this version posted September 30, 2021. The copyright holder for this preprint

(which was not certified by peer review) is the author/funder, who has granted bioRxiv a license to display the preprint in perpetuity. It is made available under aCC-BY-NC-ND 4.0 International license.

in Online Figures II-V). Cardiomyocytes, CMs (TO-PRO-3+, cTnT+); endothelial cells, ECs, (TO-PRO-3+, IB4+); other cells (TO-PRO-3+, cTnT-, IB4-). C, Representative flow cytometric data evaluating the percentage of cells (propidium iodide, $\mathrm{PI}+$ ) that were cardiomyocytes $(\mathrm{cTnT+})$ compared to non-myocytes (cTnT-) from P2, P10 and P70 PFA-fixed cardiac cell populations after the isolation and purification steps. Approximately 100,000-500,000 cells were analysed per sample and percentages were calculated as a total of the nucleated cell population $(\mathrm{PI}+)$. The gating strategy was determined per sample based on their corresponding unstained and single stained fractions (PI+ only, cTnT+ only). 


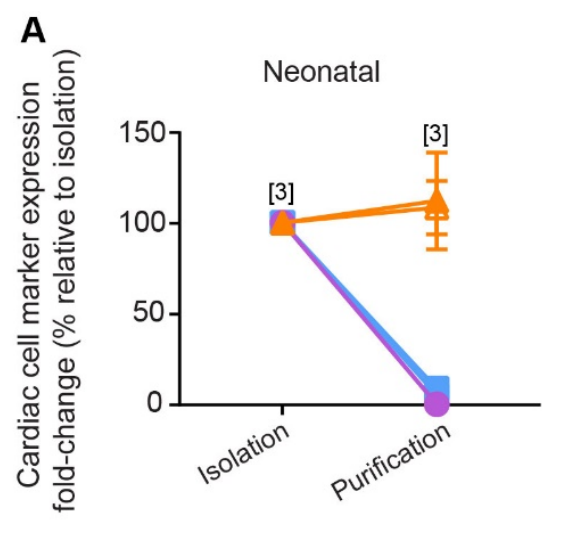

B

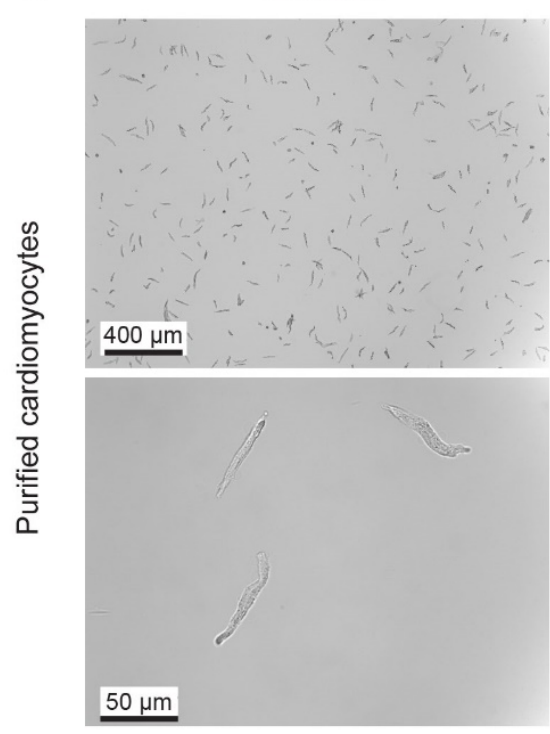

Infant

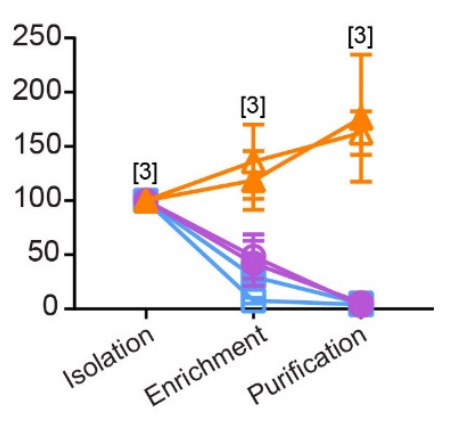

Infant
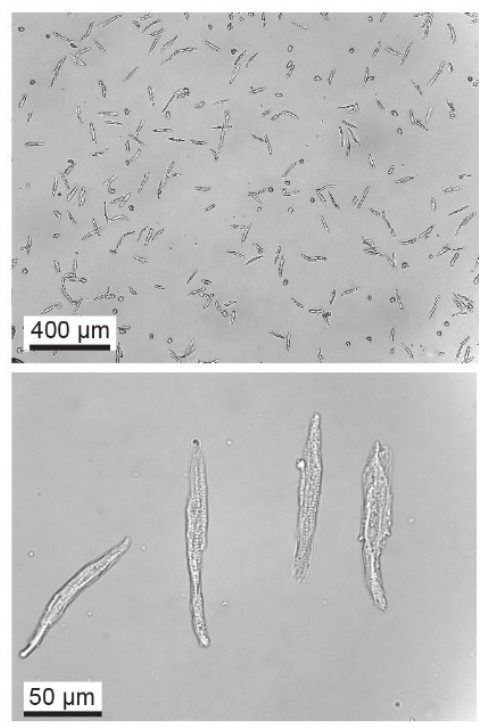

Adult

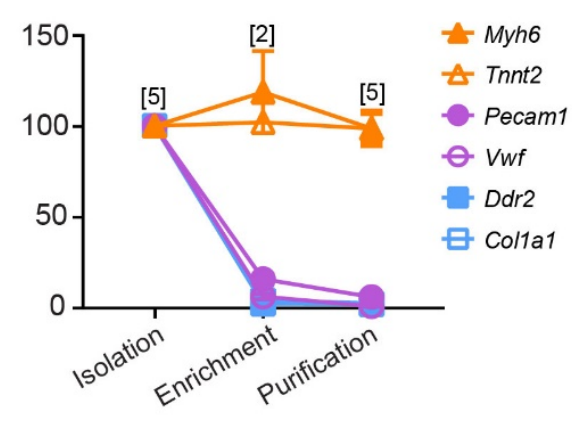

Adult

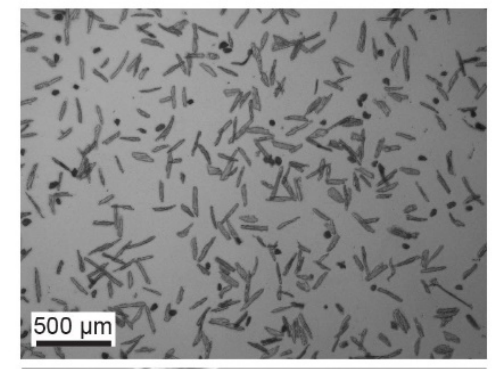

$50 \mu \mathrm{m}$

Figure 5: Cardiomyocyte purity assessed by qRT-PCR and cell morphology post-purification

A, qRT-PCR gene expression of cardiac cell markers after cardiomyocyte isolation, enrichment and purification steps, collected from: neonatal P2 (n=3); infant P10 (n=3); and adult P70 hearts $(n=2-5)$. Genes were normalized to Gapdh and fold-change calculated relative to the isolation fraction $\left(2^{-\Delta \Delta c t}\right.$ method), shown as \% (mean \pm SEM). Cardiomyocyte markers (orange): Myh6, a-myosin heavy chain and Tnnt2, cardiac Troponin T; Endothelial cell markers (purple): Pecam1, Platelet And Endothelial Cell Adhesion Molecule 1, and Vwf, von Willebrand Factor; Fibroblast markers (blue): Ddr2, Discoidin Domain Receptor 2 and Col1a1, Collagen Type I Alpha 1 Chain. B, Representative brightfield images of freshly-purified highquality cardiomyocytes ( $80-85 \%$ rod-shaped CMs) from C57BL/6J neonatal (P2), infant (P10), and adult (8-10-week-old) mouse hearts. Cells were dispersed onto slides and images were taken at 5X, 20X, 40X objectives on a Leica microscope and 4X on a Nikon Eclipse TS100 microscope. 


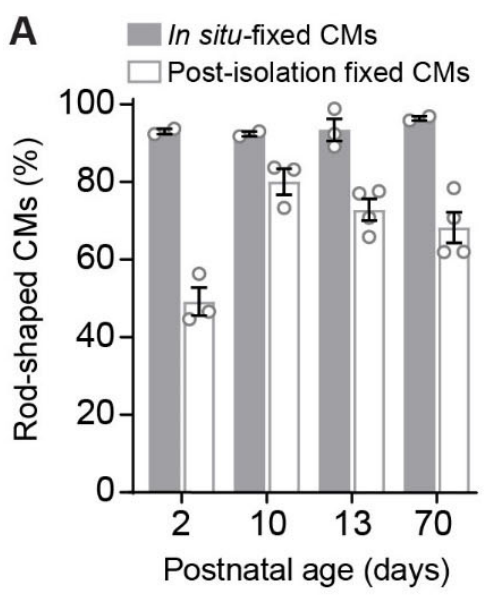

C

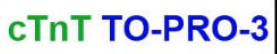

P10

\section{P2}

स्या:

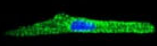

entoms

$+\infty$

thentersen

का

zorshom.

anowar

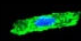

sacerys

verne

$\square$

andingese

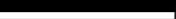

D

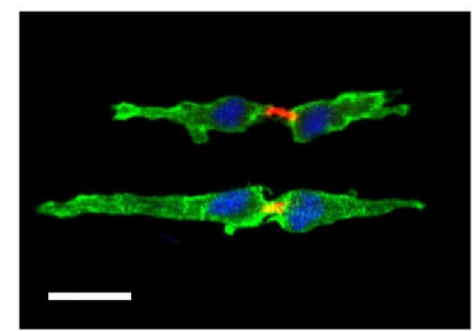

AuroraB cTnT TO-PRO-3

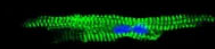

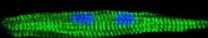

+20

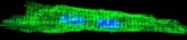

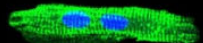

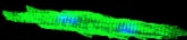

B
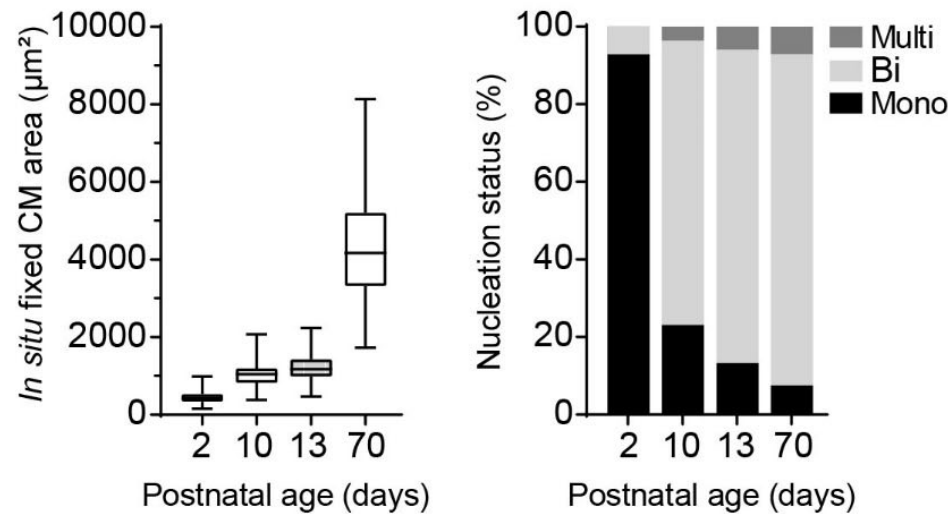

Postnatal age (days)

Postnatal age (days)

\section{P13}

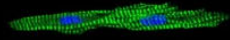

2

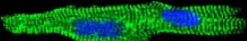

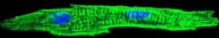

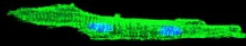

\section{5}

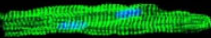

enes $=-5$

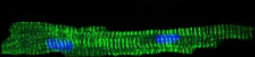

a a

P70

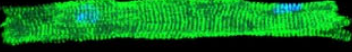

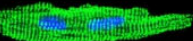

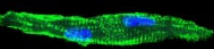
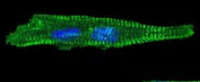

(and

-

2.
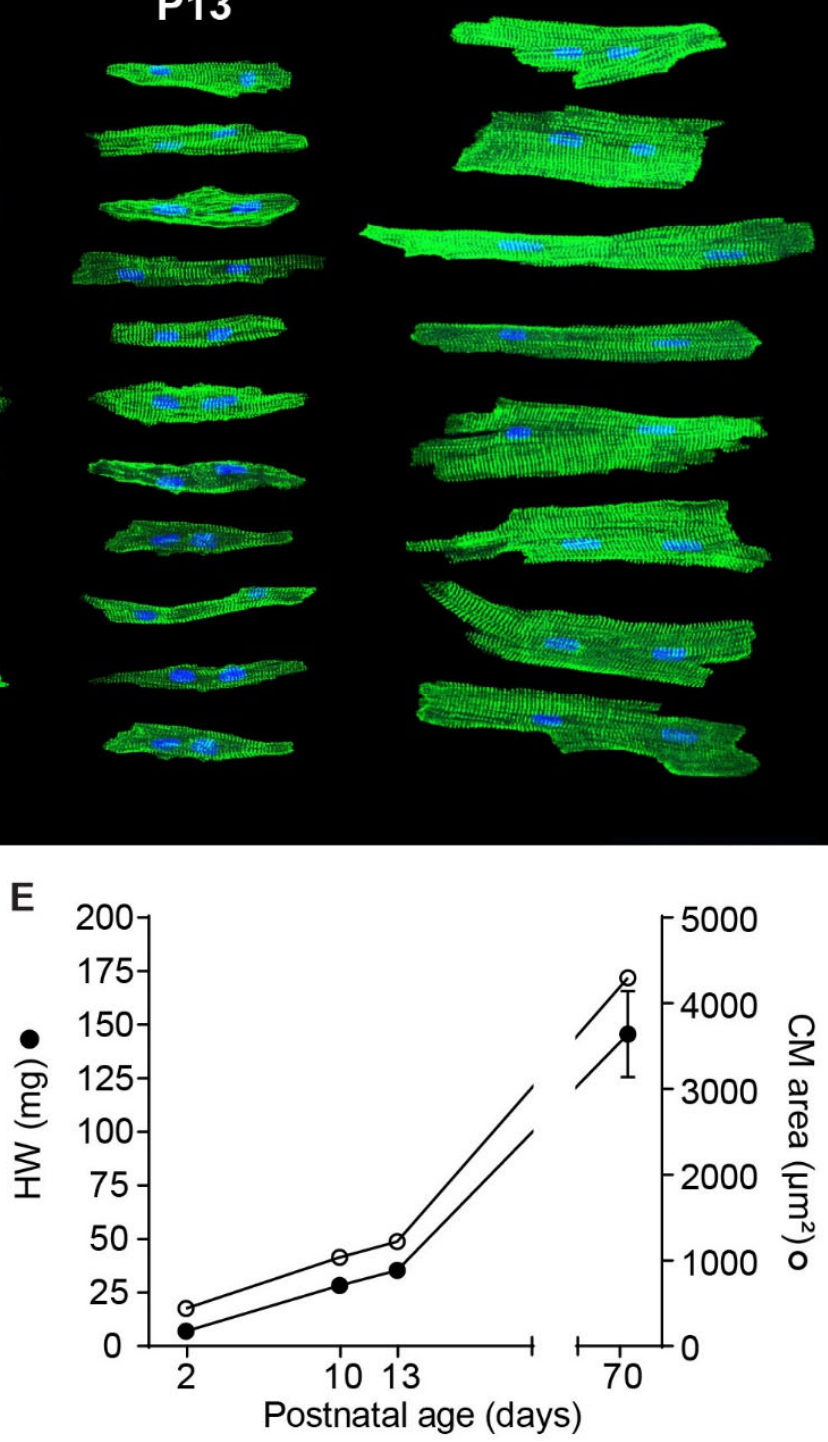


\section{Figure 6: Gross morphology of postnatal murine cardiomyocytes}

A, The percentage of rod-shaped vs round-shaped C57BL/6J murine ventricular cardiomyocytes fixed in situ or post-isolation were counted from neonatal (P2), infant (P10 and P13), and adult (P70) preparations ( $n=2-4,120-420$ cardiomyocytes) presented as mean \pm SEM. B, Cardiomyocyte area and number of nuclei per cell (see Table 3) were evaluated from confocal immunofluorescence images of in situ fixed cardiac cells at postnatal ages: P2, P10, P13 and P70 ( $n=2-3, ~ 110-300$ cardiomyocytes per age). Image was used to calculate cardiomyocyte area $\left(\mu \mathrm{m}^{2}\right)$ by planimetry. C, Representative images of in situ fixed cardiomyocytes are at postnatal ages P2, P10, P13, and P70. Cells were immunostained with the cardiomyocyte-specific marker, cTnT (green), and nuclei with DNA dye, TO-PRO-3 (blue). Scale bar is 100 $\mu \mathrm{m}$. D, Neonatal (P2) cardiomyocytes fixed in situ were captured undergoing cytokinesis as shown by positive immunostaining of the midbody with Aurora B Kinase antibody (red). Scale bar is $20 \mu \mathrm{m}$. C and D, Representative cells were selected and grouped in a horizontal position. E, Heart weight (HW, n=6-8, mean $\pm S D$, closed circles) and cardiomyocyte area ( $n=2-3$, open circles) were compared along the trajectory of postnatal cardiac growth: P2, P10, P13 and P70 (adult male) ages. 
A

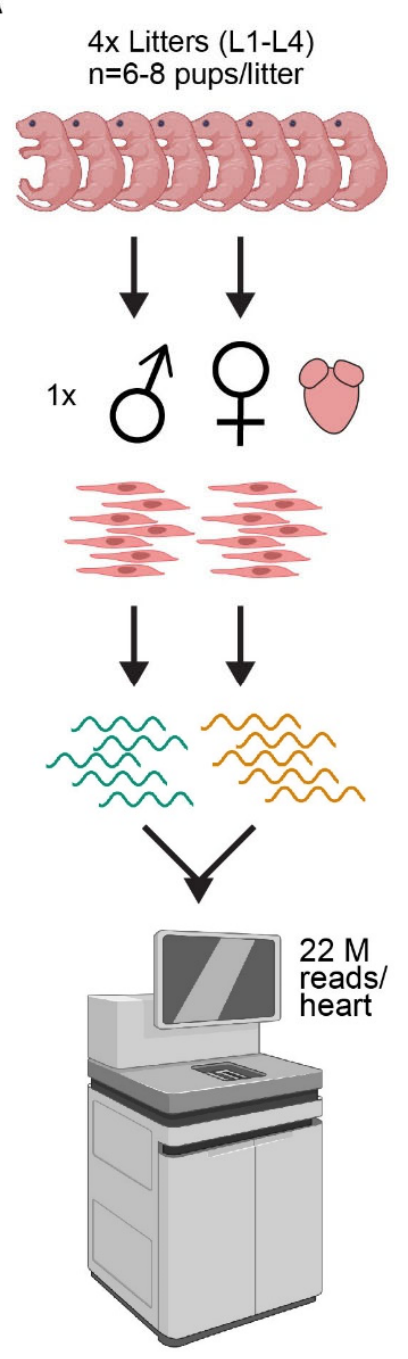

B
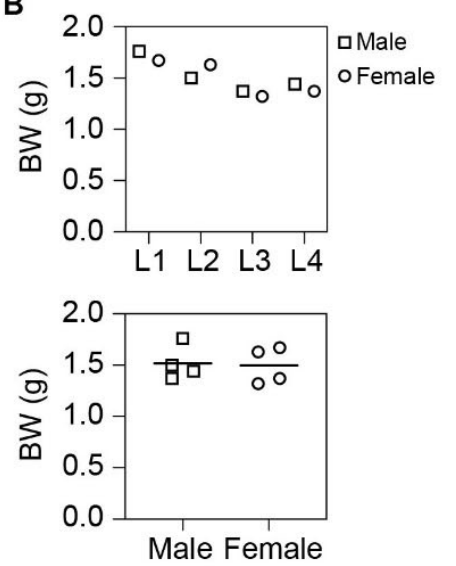

C

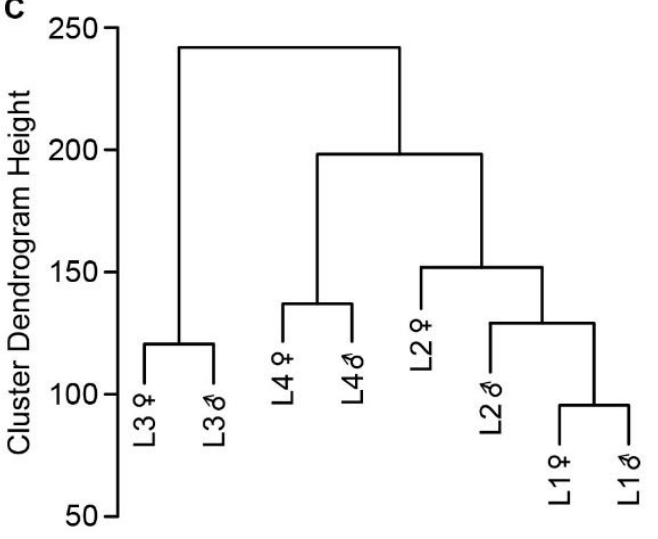

D

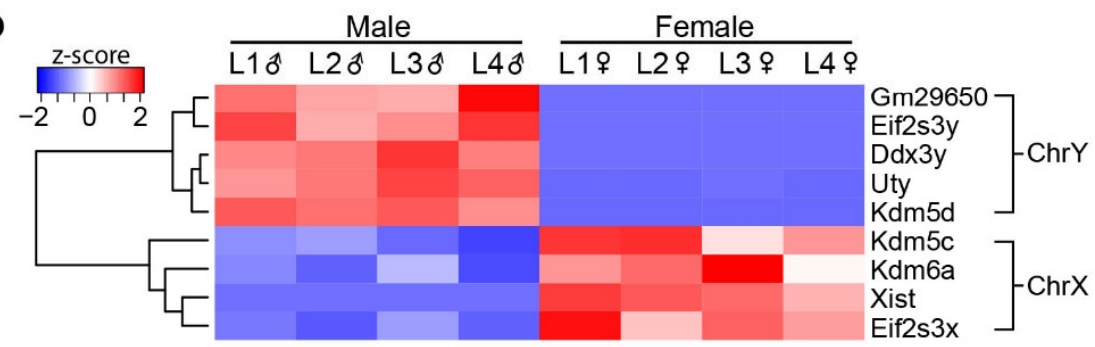

E
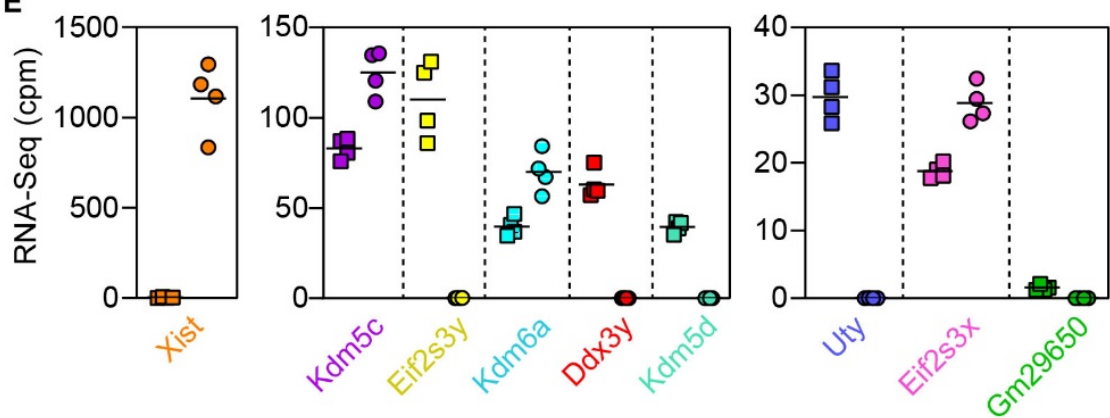

Figure 7: RNA-sequencing analysis of neonatal cardiomyocytes reveals hierarchical clustering of litters

\section{and sex differences}

A, Schematic of the experimental design. Cardiomyocytes were purified from one postnatal day 2 male and female heart per litter of 6-8 C57BL/6J mouse pups (x4 litters, L1-L4). Poly(A) RNA was extracted from cardiomyocytes and sequenced using the NovaSeq 6000 Sequencing platform generating $\sim 22 \mathrm{M}$ reads per heart. Created with BioRender.com. B, Body weights (BW) were similar between male ( $\square$ ) and female (O) littermates ( $n=4$ litters). C, Hierarchical clustering dendrogram (Ward method) based on the expression of 12,854 genes (>1 count per million, cpm, in four samples) shows clustering by litters but not sex. $D$, Heatmap shows nine differentially expressed genes (DEGs, FDR<0.005) between male and female cardiomyocytes, five genes were on chromosome $\mathrm{Y}$ (ChrY) and four on chromosome $\mathrm{X}$ (ChrX). E, Abundance (cpm) of the nine DEGs shown as dot plot and mean, ordered from highest (left) to lowest (right) counts in male ( $\square$ ) and female (O) cardiomyocytes. 


\section{Tables}

Table 1: Cardiomyocyte (CM) isolation and purifcation details

\begin{tabular}{|c|c|c|c|}
\hline & Neonate (P0-P3) & Infant (P10-13) & Adult (P70) \\
\hline \multicolumn{4}{|l|}{ Pre-cannulation } \\
\hline Heparin (1000IU/mL) & $10 \mu \mathrm{l}$ & $20 \mu l$ & $100 \mu l$ \\
\hline $\begin{array}{l}\text { Incubation time post-heparin } \\
\text { (min) }\end{array}$ & $20-30$ & $20-30$ & $20-30$ \\
\hline \multicolumn{4}{|l|}{ Cannulation step } \\
\hline Euthanasia & Decapitation & Cervical dislocation & $\begin{array}{l}2-4 \% \text { Isoflurane and } \\
\text { cervical dislocation }\end{array}$ \\
\hline Cannula & $30 \mathrm{G}$ blunt needle & 25 G blunt needle & 24 G gavage needle \\
\hline $\begin{array}{l}\text { Heart and aorta dissection and } \\
\text { cannulation time (min) } \\
\text { Perfusion step }\end{array}$ & 5 & 5 & 5 \\
\hline Flow rate (mL/min) & 1.5 & 2 & 3 \\
\hline Perfusion buffer volume (mL) & 4 & 6 & 9 \\
\hline $\begin{array}{l}\text { Perfusion time with perfusion } \\
\text { buffer (min:sec) }\end{array}$ & $2: 40$ & 3 & 3 \\
\hline $\begin{array}{l}\text { Body weight used to determine } \\
\text { enzyme conc. (g) }\end{array}$ & 5 & 8 & Actual body weight \\
\hline Digestion buffer volume (mL) & 16 & $16-20$ & $25-30$ \\
\hline $\begin{array}{l}\text { Perfusion time with digestion } \\
\text { buffer (min:sec) } \\
\text { CM isolation step }\end{array}$ & $10: 40$ & $8-10$ & $8: 20-10$ \\
\hline Buffer & Transfer buffer & Transfer buffer & Transfer buffer \\
\hline Pipette & P1000 tip & $5.8 \mathrm{~mL}$ transfer pipette & $7.7 \mathrm{~mL}$ transfer pipette \\
\hline Filter $(\mu \mathrm{m})$ & 70 & 200 & 200 \\
\hline Cell isolation time (min) & 10 & 10 & 10 \\
\hline \multicolumn{4}{|l|}{ CM enrichment step } \\
\hline Centrifugation & NA & $55 g$ for $3 \min (x 3)$ & $20 \mathrm{~g}$ for $3 \mathrm{~min}(\mathrm{x} 3)$ \\
\hline Buffer volume (mL) & NA & 8 & 10 \\
\hline \multicolumn{4}{|l|}{ CM purification step } \\
\hline Method & $\begin{array}{l}\text { Miltenyi Neonatal } \\
\text { CM Isolation kit }\end{array}$ & $\begin{array}{l}\text { CD31 Ab conjugated to } \\
\text { Dynabeads }\end{array}$ & $\begin{array}{l}\text { CD31 Ab conjugated to } \\
\text { Dynabeads }\end{array}$ \\
\hline Ab-bead volume $(\mu l)$ & 10 & 12.5 & 25 \\
\hline Ab-bead incubation time (min) & 15 & 15 & 15 \\
\hline Total time (min) & 50 & 60 & 60 \\
\hline
\end{tabular}

$\mathrm{P}$, postnatal day; $\mathrm{Ab}$, antibody. 
Table 2: Cardiomyocyte (CM) yield after the isolation and purification steps

\begin{tabular}{lllllll}
\hline Age & $\begin{array}{l}\text { CM number after } \\
\text { isolation }\end{array}$ & $\begin{array}{l}\text { Viability } \\
\text { (\%) }\end{array}$ & $\begin{array}{l}\text { Rod-shaped } \\
\text { (\%) }\end{array}$ & $\begin{array}{l}\mathbf{n} \\
\text { CM number after } \\
\text { purification }\end{array}$ & $\mathbf{n}$ \\
\hline Neonate (P2) & $1.56 \pm 0.48 \times 10^{6}$ & 100 & $53(\sim 30-85)$ & 72 & $1.03 \pm 0.33 \times 10^{6}$ & 56 \\
Infant (P10) & $1.62 \pm 0.39 \times 10^{6}$ & $70(\sim 60-90)$ & $70(\sim 60-90)$ & 69 & $0.96 \pm 0.29 \times 10^{6}$ & 44 \\
Infant (P13) & $1.65 \pm 0.44 \times 10^{6}$ & $70(\sim 60-90)$ & $70(\sim 60-90)$ & 25 & $0.8 \pm 0.21 \times 10^{6}$ & 25 \\
Adult (P70) & $2.21 \pm 0.36 \times 10^{6}$ & $72(\sim 60-90)$ & $72(\sim 60-90)$ & 27 & $1.6 \pm 0.29 \times 10^{6}$ & 19 \\
\hline
\end{tabular}

Table 3: Estimates of cardiomyocyte DNA, RNA and protein yield post-purification

\begin{tabular}{lllll}
\hline & Neonatal (P2) & Infant (P10) & Infant (P13) & Adult \\
\hline Binucleated $(\%)$ & 7 & 73 & 81 & 85 \\
Cell area $\left(\mu \mathrm{m}^{2}\right)$ & $446 \pm 148$ & $1041 \pm 316$ & $1226 \pm 333$ & $4298 \pm 1278$ \\
DNA yield $(\mathrm{pg} /$ cell) & 7.6 & $13.8(2)$ & $\mathrm{NA}$ & $12.1(2)$ \\
RNA yield $(\mathrm{pg} /$ cell) & $7.3(20)$ & $18.1(12)$ & $23.5(25)$ & $31.1(12)$ \\
RIN score & $8.9(20)$ & $9(12)$ & $8.6(25)$ & $8.5(12)$ \\
Protein yield $(\mathrm{pg} /$ cell) & $105(3)$ & $312(3)$ & $\mathrm{NA}$ & $4026(3)$ \\
\hline
\end{tabular}


bioRxiv preprint doi: https://doi.org/10.1101/2021.09.30.462562; this version posted September 30, 2021. The copyright holder for this preprint (which was not certified by peer review) is the author/funder, who has granted bioRxiv a license to display the preprint in perpetuity. It is made available under aCC-BY-NC-ND 4.0 International license. 